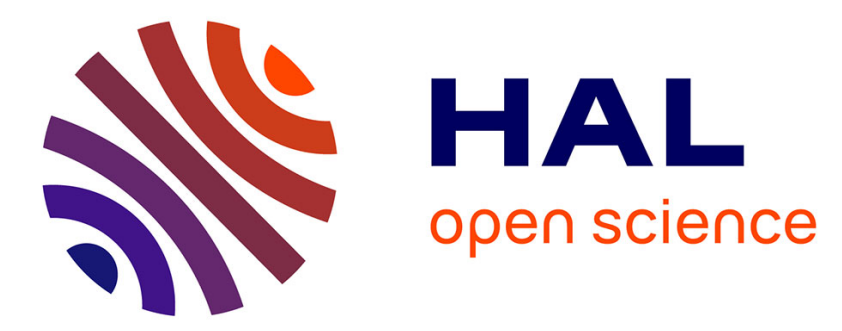

\title{
Micro gas preconcentrator in porous silicon filled with a carbon absorbent
}

El Hadji Malick Camara, Philippe Breuil, Danick Briand, Laurent Guillot, Christophe Pijolat, Nicolaas F de Rooij

\section{- To cite this version:}

El Hadji Malick Camara, Philippe Breuil, Danick Briand, Laurent Guillot, Christophe Pijolat, et al.. Micro gas preconcentrator in porous silicon filled with a carbon absorbent. Sensors and Actuators B: Chemical, 2010, 148 (2), pp.610-619. 10.1016/j.snb.2010.05.054 . hal-00508020

\section{HAL Id: hal-00508020 \\ https://hal.science/hal-00508020}

Submitted on 2 Aug 2010

HAL is a multi-disciplinary open access archive for the deposit and dissemination of scientific research documents, whether they are published or not. The documents may come from teaching and research institutions in France or abroad, or from public or private research centers.
L'archive ouverte pluridisciplinaire HAL, est destinée au dépôt et à la diffusion de documents scientifiques de niveau recherche, publiés ou non, émanant des établissements d'enseignement et de recherche français ou étrangers, des laboratoires publics ou privés. 


\title{
Micro gas preconcentrator in porous silicon filled with a carbon absorbent
}

\author{
El Hadj iI Malick Camara ${ }^{(1,2)}$, Philippe Breuil(1)*, Danick Briand(2), LaUrent \\ GuIllot $^{(2)}$, CHRISTOPHE PIJ OLAT ${ }^{(1)}$, NiCOlaAs DE RoOIJ ${ }^{(2)}$
}

(1) Ecole Nationale Supérieure des Mines de Saint Etienne, Centre SPIN ; Département MICC ; LPMG UMR CNRS 5148 ; 158 Cours Fauriel ; 42023 Saint-Étienne Cedex 2, France

(2) Institute of Microtechnology, University of Neuchâtel Jaquet-Droz 1, PO Box 526, CH 2002 Neuchâtel, Switzerland Collaboration

\begin{abstract}
This paper presents the development of a gas preconcentrator based on a micro-channel in porous silicon filled with carbon nanopowders by a micro-fluidic process. The particularity of this device is its applicability in the fields of atmospheric pollution monitoring by targeting VOCS (volatiles organic compounds). Various designs of micro-devices have been investigated and a special focus has been dedicated to the carbon adsorbent. The optimization of the device and its operation were driven by its future application in outdoor environments. The benefits of using porous silicon to ease the fixing of the carbon absorbent in micro-channels and to modify the gas desorption kinetic are also investigated. Results on a device based on a carbon adsorbent powder filled in a porous silicon micro-channel for benzene preconcentration are reported.
\end{abstract}

Keywords:

Preconcentrator; Gas sensors; Micro-channel; Porous silicon

\section{Introduction}

In the field of gas detection, one major trend is to miniaturize analytical techniques. In such technological developments, the gas pre-conditioning is usually very important. This may involve, firstly, the modification of a gas mixture, for example to improve the selectivity of a detection device [1], [2], [3] and [4], secondly, the effect of preconcentration in order to increase the sensibility of the detector [5], [6] and [7].

Indeed, in some applicative environments the concentration of gas is too small and therefore a preconcentration unit at the entrance of the analytical device is needed [8] and [9]. When a preconcenrator is used, the gas mixture to be analyzed flows through it and is accumulated during some time, then the mixture is desorbed by a temperature pulse and brought to the detector [10], [11], [12], [13] and [14].

Requisite specifications, such as small system size, high performance, low power budget, and quick time response lead to the microfabrication of the key components of the analytical systems. Recent studies have shown that the fabrication of such micro-analytical systems on silicon technology offers clear advantages over conventional systems, but the hybrid integration of the components, using plastic, metal, or silicon/glass manifolds, becomes increasingly interesting because of the numerous potential applications. The benefits of using this approach are the possibility to optimize the individual components composing the system

\footnotetext{
*Corresponding author : pbreuil@emse.fr
} 
and it enables their replacement in a modular fashion [15] and [16]. Moreover, the miniaturization of the preconcentrators leads to superior heating rates, reduced power consumption and allows its integration in portable miniaturized analytical instruments, such as micro gas chromatographs and ion mobility spectrometers.

In a previous study a catalytic microreactor has been developed to act as a filter to improve the selectivity to methane of a sensor placed downstream of the device [17]. The present work aims at developing a silicon preconcentrator device based on this concept, with new approaches in the design as well as in the choice of materials, replacing the catalyst by a gas absorbent material. One difference with other work performed on this topic is that the adsorbent material is here introduced in the form of powder in a fluidic solution [18]. We have reported recently on the feasibility of this concept using a carbon nanopowder [19]. Another strategy to increase the specific area, and consequently the gas adsorption, is to use porous silicon. By varying the parameters used for the formation of porous silicon, micro-, meso- or macropores in silicon can be realized [20], [21] and [22]. The high specific area offers by porous silicon can be used as an interesting support to increase the quantity of adsorbent materials fixed in the micro-channels when made of this material. Besides this, porous silicon presents in itself a high adsorption capacity of molecules which has been already applied directly to the detection of gases. The association of porous silicon with the carbon nanopowders deserves to be explored, since it could lead to some superposition of their gas adsorption capabilities and results in improved performances.

The devices in this study have been developed targeting the preconcentration of benzene. This gas is considered as a relevant representative for several types of applications related to atmospheric pollution control (BTEX compounds).

Except the design of the micro-channel and the adsorbent material proprieties, the performances of the device are closely related to experimental conditions and detection system. At this end, experimental conditions chosen in this work have been obtained from a series of experimental optimization and theoretical modelling which are not the main subjects of this paper.

\section{Experimental}

\section{II.1. Preconcentrator design}

Globally, the micro-channel consists in silicon micro-channels which can receive the adsorbent material, with inlet and outlet suitable for fluidic connections using metallic capillaries and are sealed with a glass cap. The device includes also a platinum micro-heater on the backside.

The depth of the micro-channel, for the inlet, the outlet and the preconcentration chamber, was defined at $325 \mu \mathrm{m}$, corresponding to the external diameter of the capillaries used as fluidics interconnections. Micro-channels with three different shapes were designed in order to ease the introduction of the carbon nanopowders. Figure 1 shows two micro-channels respectively in "straight" and "zigzag" designs with the magnification of its structures. The "zigzag" design ("V" shaped structures), contributes to improve the carbon deposition by stopping it when injected into the micro-channel. While the "straight" design ("wall" shaped structures) leads to an increase of the available area for deposition since the surface of the walls constitute a binding area for adsorbent particles. And lastly, the "neutral" design without structures was made in order to have a reference to determine the benefits or not to have structures. At the inlet and outlet, a system of channels was designed targeting a uniform distribution of the gas or liquid flow. The channels can be made of silicon or porous silicon. The use of porous silicon offers the possibility of increasing the quantity of the deposited adsorbent material and thus the specific area in a given volume. The dimensions of the designs are summarized in Table 1. 
(a)

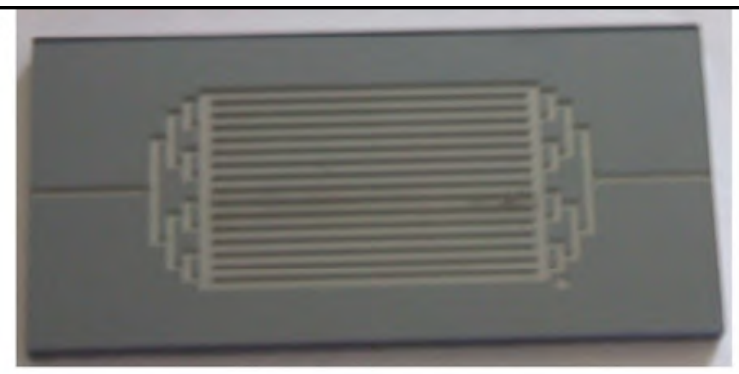

(c)

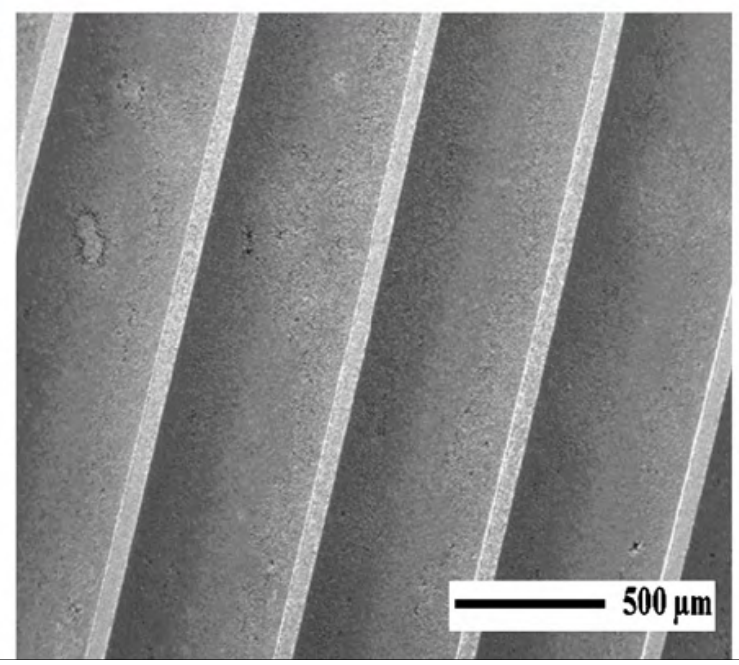

(b)

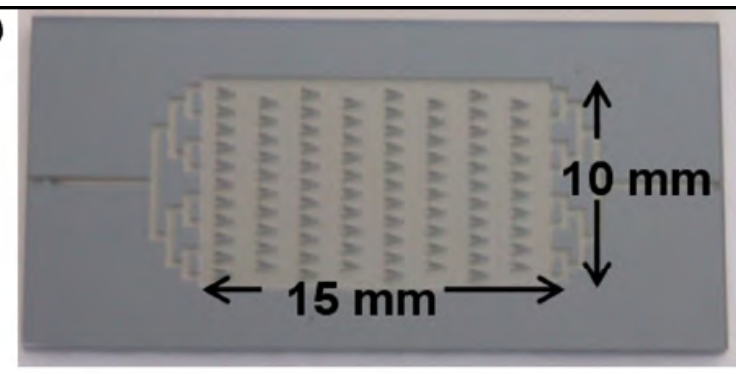

(d)

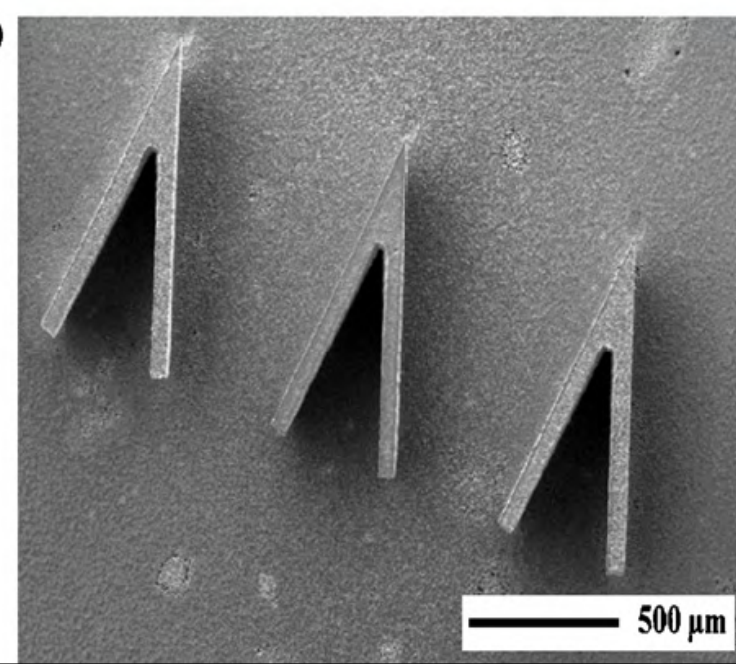

Figure 1: (a) Top view of a micro-channel in "straight" design, (b) top view of a micro-channel in "zigzag" design, (c) magnification of walls in straight design and (d) magnification of structures in "zigzag" design.

Table 1: Dimensions of the preconcentrators.

\begin{tabular}{|l|l|l|l|}
\hline \multicolumn{1}{|c|}{ Design of micro-channels } & \multicolumn{1}{c|}{ Neutral } & \multicolumn{1}{c|}{ Straight } & \multicolumn{1}{c|}{ Zigzag } \\
\hline Length $\times$ width $[\mathrm{mm}]$ & $30 \times 15$ & $30 \times 15$ & $30 \times 15$ \\
\hline Vol. of $\mu$-micro-channel $\left[\mathrm{mm}^{3}\right]$ & 48.75 & 41.92 & 44.07 \\
\hline Walls or pillars width $[\mu \mathrm{m}]$ & No & 50 & 50 \\
\hline
\end{tabular}

\section{II.2. Porous silicon formation}

As mentioned previously, an objective of this study is to fill in short time a sufficient quantity of adsorbent material in the micro-channel. To that end, the use of micro-channels made of porous silicon appears particularly attractive. The size, shape and depth of pores depend on several parameters such as the concentration of the bath, the doping and the resistivity of the wafer, the applied current density and the etching time [20]. In some cases, an illumination or a metallic deposition on the backside of the wafer is necessary to facilitate the transfer of charge carriers between the solution and the substrate. However, an unproper choice of these parameters may have harmful consequences on the pores quality or even damage the microchannel since the anodic etching is governed by three regimes namely the "electropolishing" regime, the "porosification" regime and at last "transitional" regime.

The porous silicon micro-channel was obtained by anodic etching of silicon in a bath of $\mathrm{HF}$ (50\%) and $\mathrm{EtOH}$ in a ratio of 1:1. This technique is an electrochemical etching during which chemical phenomena are linked to reciprocal exchanges of electrical energy that occur at the interface of two conductor systems (electronic and ionic). It is an efficient method to obtain spongy or columnar layers of silicon. The elaboration of macro and microporous silicon requires the control of some main parameters such as the silicon substrate doping, the concentration of the HF bath, the anodic current density and the etching time. The choice of substrate doping is a determining factor on the nature of pores formed. The wafer doping 
determines the movement of charge carriers when a potential difference is applied between the electrodes of the HF bath.

To this end, the silicon wafers used for the anodic etching were n- and p-type with resistivities varying from 0.015 to $5 \Omega \mathrm{cm}$ and different current densities between 40 and $300 \mathrm{~mA} / \mathrm{cm}^{2}$ were applied on these wafers. This evaluation was done in order to define two sets of optimum processing conditions to realize micro- and macroporous silicon pores. The etching time determines the penetration depth of the pores in the substrate, more the latter longer more the pores formation goes deeper. To avoid the weakening of micro-channels, we targeted a depth of the pores of about $100 \mu \mathrm{m}$. Since the pores obtained by anodic etching have a conical growth i.e. the pores diameter increases with the depth, and therefore, after the pore formation, about few micrometers of silicon were etched by reactive ion etching (RIE) in order to open these pores. After the RIE stage, the wafers were observed in SEM to determine the pores distribution on the surface and then they were cleaved in order to observe the depth of these pores. And following these characterizations, the wafers went through BET measurements to determine their specific area.

\section{II.3. Carbon insertion}

In relation to the size of our carbon particles, the contribution of the silicon micropores on the filling of carbon will be very limited since the size of carbon particles has the same order of magnitude than the diameter of pores. As a result, only the macroporous silicon, both on flat substrates and on micro-channels, has been used as a support for the carbon deposition while the devices made of microporous silicon were directly applied as preconcentrators, without any adsorbent material deposition.

A carbon nanopowder from the company Sigma-Aldrich (CAS number 7440-44-0) has been chosen as an adequate adsorbent for a fluidic deposition because of its distribution of sizes between 30 and $100 \mathrm{~nm}$ since the metallic capillaries used for fluidic connection have an internal diameter of $220 \mu \mathrm{m}$ and its specific surface close to $100 \mathrm{~m}^{2} / \mathrm{g}$ suitable for the adsorption of same volatile organic compounds (VOCs).

In order to study the fixing of the carbon particles in micro-channels, carbon was deposited in a first step on silicon substrates by the wetting method which consists in immersing the silicon chips in the carbon solution. The latter is basically composed of water, carbon and a few drops of dispersant (Company Roche- Nonidet P40) to homogenize the mixture. The quantity of carbon deposited is a function of the substrate nature and the number of times this operation was repeated. The porous aspect of silicon represents a key parameter to improve the fixing of the carbon particles. In a second step, the carbon was inserted in the sealed silicon micro-channels. After testing several methods of filling up the micro-channel with carbon from a fluidic solution, we faced overpressure in the micro-channels, especially by injecting the carbon suspension with a push-syringe. To overcome this problem, a new method was implemented. It consists in putting the device under vacuum for making easier the circulation of the suspension through the micro-channels by a difference of pressure between preconcentration chamber of the micro-device and liquid suspension. Changeable capillaries were used in order to reduce the overpressure created by their blocking. Results have been characterised using scanning electron microscopy (SEM) and by measuring the weight of deposited carbon.

\section{II.4. Preconcentrator fabrication}

The processing of these preconcentrators is simple. Silicon micro-channels are directly dry plasma etched by deep reactive ion etching (DRIE) using a thick photoresist mask. In the case of porous silicon channels, prior to the DRIE, a silicon nitride film is deposited to act as a masking layer during the porous silicon formation. Then, for both types, a thermal oxide is grown prior to their sealing with a glass cover by anodic bonding. A more detailed description of the process is given in the following paragraphs.

Following a photolithographic step with a thick AZ4562 photoresist, the inlet, outlet and preconcentration chamber of the micro-device are DRIE etched in the silicon wafer to a depth of $325 \mu \mathrm{m}$ (Figure $2 \mathrm{~b}$ ). If desired, the porous silicon was produced following the procedure 
described in Section II.2. In that case, a 500 nm-thick LPCVD low-stress $\mathrm{Si}_{3} \mathrm{~N}_{4}$ thin film was first deposited (Figure 2a) and was used as an etch mask during this step (Figure 2c). Therefore, porous silicon was formed on all the unprotected area of the silicon micro-devices, including the sidewalls of the micro-channels. In order to improve the adhesion of the carbon adsorbent powder that will be deposited afterwards in the micro-channels made or not of porous silicon, $25 \mathrm{~nm}$ of thermal oxide were grown to make them become hydrophilic and also to facilitate the adhesion of carbon particles. Finally, the micro-channels were sealed with a Borofloat glass wafer by anodic bonding (Figure 2d) and diced according to the dashed line showed in Figure 2e revealing the inlet and outlet for the fluidic connectors.

(a)

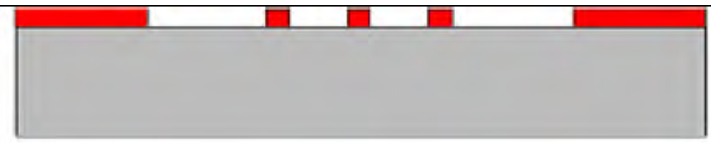

(c)

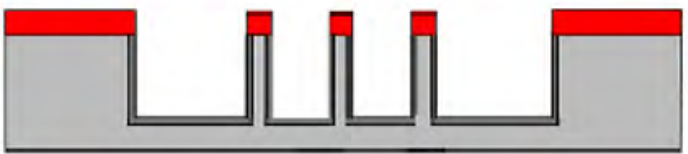

(e)

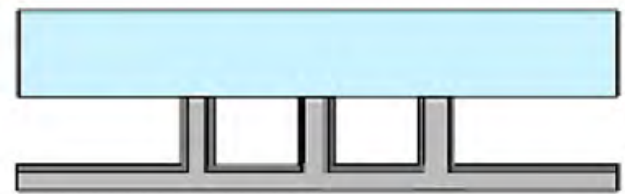

(b)

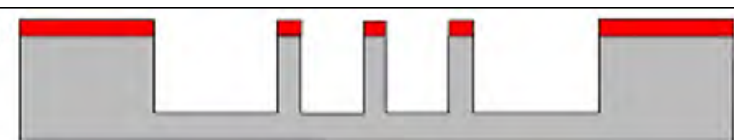

(d)

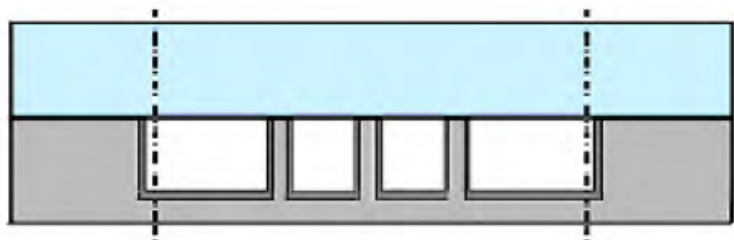

(f)

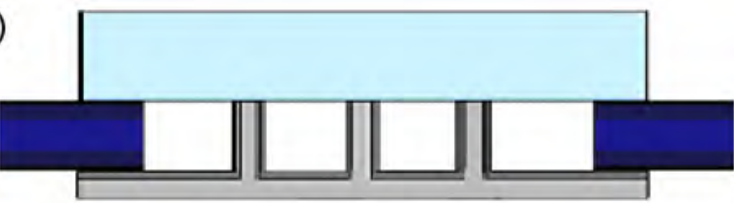

\section{Low-stress $\mathrm{Si}_{3} \mathrm{~N}_{4}$ \\ Bor ofloat glass wafer \\ Metallic capillaries (steel) \\ Silicon substrate \\ Porous Silicon Iayer}

Figure 2: Fabrication process of the preconcentrator, which is illustrated here with the "straight" design.

In order to have an autonomous component, for either the thermal treatments of the absorbent materials and the desorption of trapped gases, a platinum heater is integrated on the backside of the device by screen printing and the electrical connections are made with gold wires pasted on a platinum lacquer. This heating element is used to heat the device at temperatures up to $500{ }^{\circ} \mathrm{C}$ with a very homogeneous distribution of the temperature considering the good thermal conductivity of the silicon, as it was reported in our previous work on microreactor for gas-solid catalyst [17] and as shown in Figure 3 on the right hand side. The platinum paste used for the heater deposition is commercialized by the company Electro-Science Laboratories (ref. 5545).

Once the devices filled with carbon, the fluidic connections are made with metallic capillaries (steel) having $220 \mu \mathrm{m}$ of internal diameter and fixed with ceramic cement using a special procedure so as not to block the connectors during the sealing (Figure 2f). Figure 3 shows a micro-preconcentrator at the final stage of its fabrication after the carbon deposition, including the integrated heater, with its electrical connections appearing on the picture, and the metallic capillaries used as fluidic connectors. 


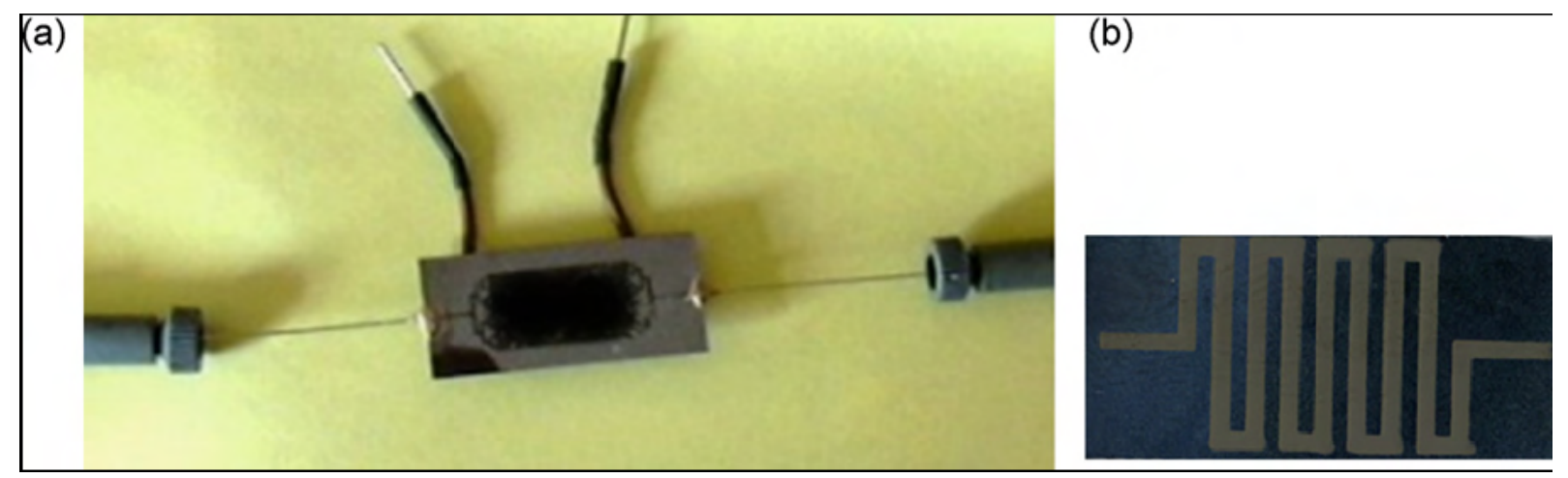

Figure 3: (a) Micro-channel in porous silicon filled with carbon with metallic gas capillaries including the integrated heater, with its electrical connections and (b) optical image of the screen-printed heater on backside of the micro-channel.

\section{II.5. Preconcentration experiments}

Benzene vapor has been chosen as target gas. The weak concentrations of benzene between 10 and $500 \mathrm{ppb}$ are generated using a gas cylinder of air with $100 \mathrm{ppm}$ of benzene and a dilution bench made with two mass-flow controllers. The pressure measurement upstream and downstream of the mass-flow controllers allows verifying the good operation of the mass flow in spite of the driving head. This device enables to exactly generate very weak concentrations in the sub-ppm range (Figure 4). The first experiments were dedicated to the validation of the test set-up. No adsorption of benzene occurs in the set-up when tested with micro-devices without the absorbent. Indeed, when benzene was injected in the channel (100 ppm), the latter was detected by the sensor without retention time and no desorption peak was then observed during the heating step.

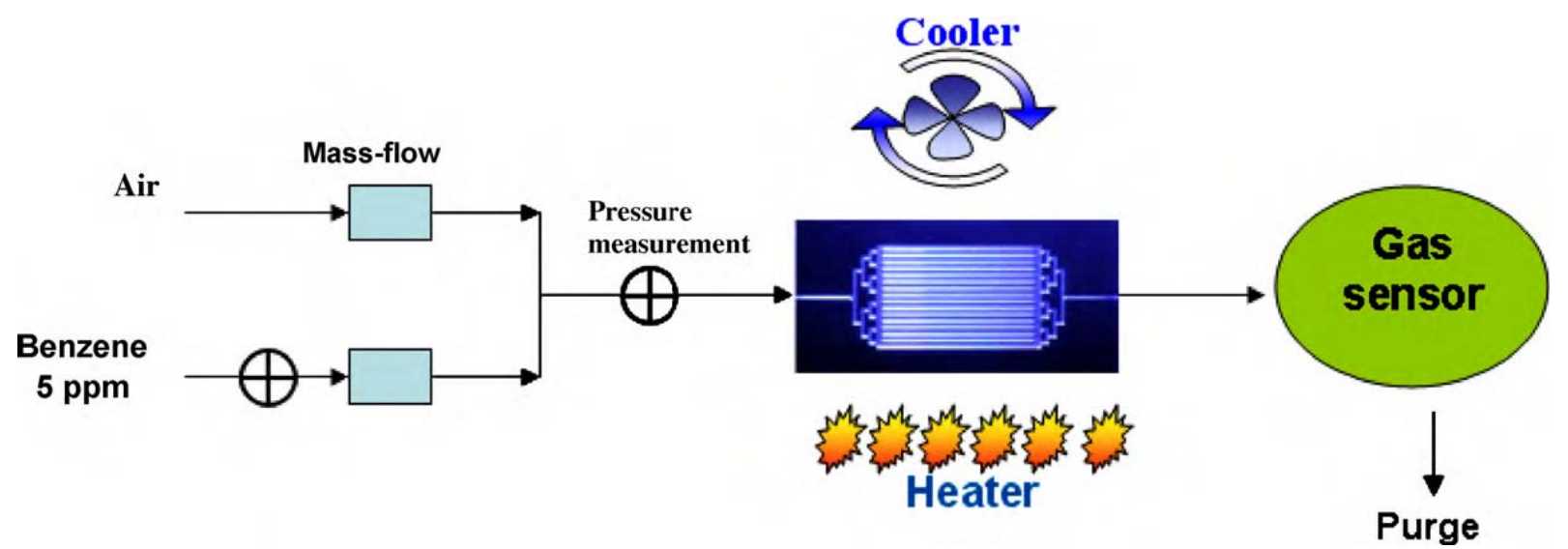

Figure 4: Schematic illustration of the micro-preconcentrator test bench.

Four main parameters are of importance for the optimum operation of a preconcentrator device with a given geometry and filled with a fixed quantity of specific absorbent material, the gas flow rate during the gas adsorption and desorption phases, the heating rate during the gas desorption, the duration of the gas adsorption and desorption phases, and the proximity of the gas outlet to the detector and its detection volume (volume between the micropreconcentrator and the detector plus the gas volume of the detector).

The miniaturization of such device imposes us a limitation on the gas flow rate, but for preconcentration, high flow rates are preferred in order to increase preconcentration factor for a given time of adsorption. However, a high gas flow can cause significant pressure drop thus weakening the device and modifying the physical chemistry phenomena. In this study, the use of metallic gas capillaries with $220 \mu \mathrm{m}$ of internal diameter as fluidic connectors allowed us to generate a flow of $167 \mathrm{~mL} / \mathrm{min}$ either-or 2 bars of relative pressure without consequence on the preconcentration. Regarding the optimization of the preconcentration, 
the adsorption phase flow was set at $167 \mathrm{~mL} / \mathrm{min}$, which allowed us to inject a significant quantity of pollutant in a short time, while the desorption phase flow was maintained at $33 \mathrm{~mL} / \mathrm{min}$ to avoid an important dilution of the desorbed quantity. Likewise, to avoid a considerable detection volume, the metallic capillary at the outlet of the micropreconcentrator was directly connected to the inside of the detector through its packaging (Sensor from FIGARO ref. 2620), and the latter was then calibrated in order to correct the influence of the gas flow on the characteristics of its response. The calibration curb of the sensor has been realized for different concentrations in the same conditions (flow rate and capillary inside the packaging). Le detection limit of this sensor is estimated about $15 \mathrm{ppb}$.

As mentioned previously, the effectiveness of the preconcentration is closely linked to the physical chemistry properties of the adsorbent, the desorption protocol, the detection system and its dead volume. Therefore, the heating rate is an important element for increasing the preconcentration factor. In fact, it is well known, that the maximum of the desorption peak is an increasing function of the heating rate. Higher the heating rate is, narrower and higher the desorption peak is i.e. the maximum of the desorption more important and consequently a significant factor of preconcentration (Figure 5). According to this observation, the preconcentration tests were performed with a heating rate of $160^{\circ} \mathrm{C} / \mathrm{min}$, which corresponds to the maximum rate that can reach the heating resistance deposited on the backside of the micro-channels. And also, in order to follow the evolution of the desorption temperature and to determine the activation energy of this desorption characteristic of a given type of micropreconcentrator, we used different heating rates of 5,10 and $20^{\circ} \mathrm{C} / \mathrm{min}$. The temperature of desorption has been set at $200^{\circ} \mathrm{C}$ after its optimization performed in previous experiments with charges of carbon [19].

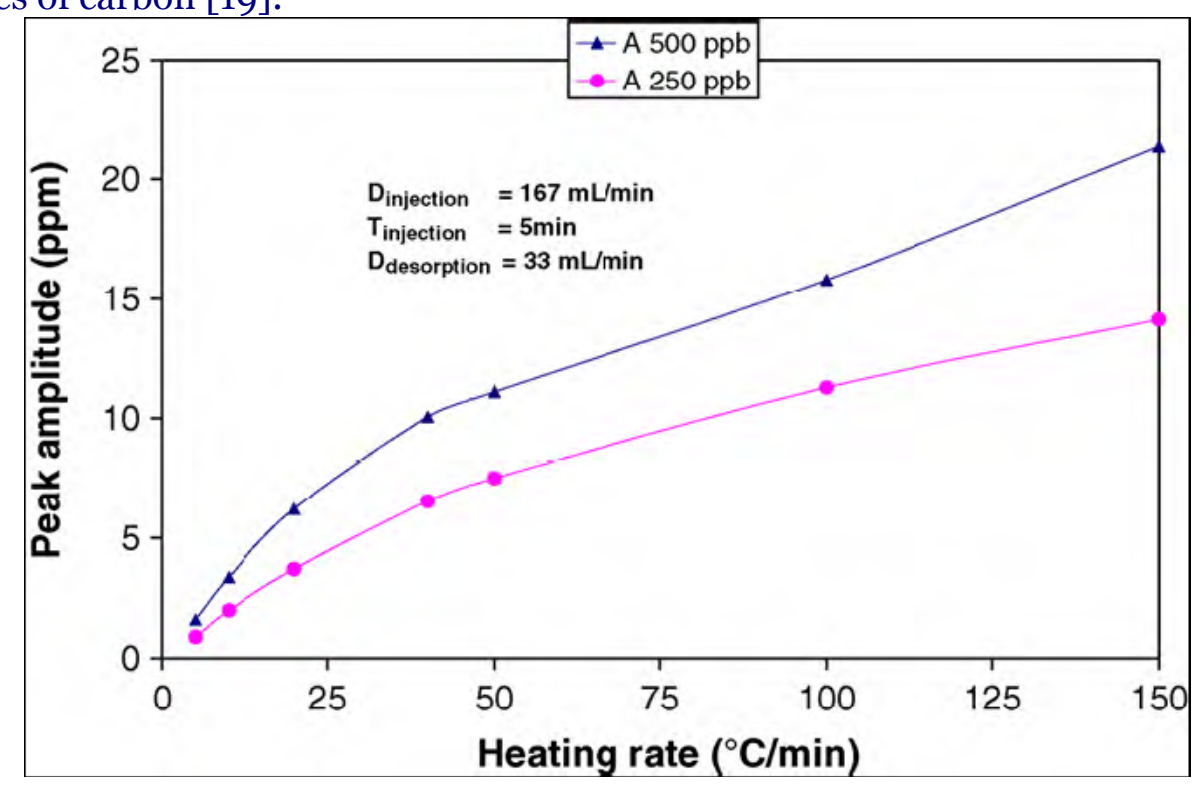

Figure 5: Demonstration of the dependence between the amplitude of the desorption peak and the heating rate.

Finally, the increase of the adsorption time can lead to an enhancement of the desorption peak amplitude but in the mean time cause a longer preconcentration cycle which for some applications might not be desirable. In addition, the optimization experiments made on the duration of the desorption phase showed that the desorption is almost complete after 4$5 \mathrm{~min}$. To this end, the adsorption and desorption times were maintained constant all through the experiences and lasted for 5 min since for these targeted applications as the pollution monitoring, a short preconcentration cycle is more appropriate.

So it is very difficult to define a preconcentration factor since, for a given preconcentrator, the "amplification" of the concentration is closely related to these four external parameters. However, we will measure a "practical" preconcentration factor which we define as the ration between the maximum of the measured concentration during the desorption phase and the concentration of the injected gas. This factor will be largely lower than the "theoretical" 
preconcentration factor because of the significant detection volume needed by the sensor system which is yet not optimized.

\section{Results and discussions}

\section{III.1. Porous silicon formation}

Preliminary experiments on unstructured wafers have shown that the n-type substrate led mostly to a non-uniform porosity, unlike the p-type substrate which has an excellent diffusion length of minority charge carriers. The resistivity of the wafer is also a significant factor because the p-type wafers with low resistivity lead often to micropores in spite of high-applied current densities while n-type substrates led to macropores for these same resistivity ranges. The current density is an increasing function of the pore size but a high current density caused an electropolishing regime manifesting by the stripping of the substrate.

As a first step, macroporous silicon was realized on $5 \Omega \cdot \mathrm{cm}$, n-type, (1 o o)-oriented and $525 \mu \mathrm{m}$-thick flat substrates with a current density of $40 \mathrm{~mA} / \mathrm{cm}^{2}$ but the result was unsatisfying because there was a non-uniform distribution of pores with particular areas of porous high density and non-porous areas consequence of poor diffusion of charge carriers (Table 2). Nevertheless, we chose to test the adhesion of carbon particles on pieces of theses wafers on which the porosity seemed locally uniform. The results of these tests are described in Section III.2.

Table 2: Several porous silicon characteristics with their different processing parameters and in some case a RIE etching.

\begin{tabular}{|c|c|c|c|c|c|c|c|}
\hline $\begin{array}{l}\text { Wafer } \\
\text { type }\end{array}$ & $\begin{array}{l}\text { Wafer } \\
\text { resistivity } \\
{[\Omega \mathrm{cm}]}\end{array}$ & $\begin{array}{c}\text { Current } \\
\text { density } \\
{\left[\mathrm{mA} / \mathrm{cm}^{2}\right]}\end{array}$ & $\begin{array}{c}\text { Etching } \\
\text { time } \\
\text { [min] }\end{array}$ & $\begin{array}{c}\text { Pore } \\
\text { diameter } \\
{[\mathrm{nm}]}\end{array}$ & $\begin{array}{c}P S \\
\text { thickness } \\
{[\mu \mathrm{m}]}\end{array}$ & $\begin{array}{l}\text { Etch rate } \\
{[\mu \mathrm{m} / \mathrm{min}]}\end{array}$ & $\begin{array}{c}\text { Specific } \\
\text { area } \\
{\left[m^{2} / g\right]}\end{array}$ \\
\hline \multicolumn{8}{|c|}{ Unstructured wafers } \\
\hline$p$ & 0.015 & 150 & 6 & $8-13$ & $1-20.4$ & 3.40 & 3.07 \\
\hline$p$ & 5 & 300 & 30 & $11-25$ & $N A$ & $N A$ & 0.10 \\
\hline$n$ & 5 & 40 & $2 O$ & $348-1060$ & $1-136$ & 6.80 & 2.33 \\
\hline$n$ & 5 & 40 & $2 O+R I E$ & $871-1920$ & $2-130$ & 6.80 & 2.58 \\
\hline \multicolumn{8}{|c|}{ Silicon micro-channels } \\
\hline$p$ & 5 & 70 & $6 O+R I E$ & $53-252$ & $N A$ & $N A$ & 27.27 \\
\hline$n$ & 5 & 60 & $45+R I E$ & $\begin{array}{l}1023^{-} \\
2350\end{array}$ & 140 & 2.66 & 44.5 \\
\hline
\end{tabular}

So as to make uniform the distribution of charge carriers across the wafer and thus uniform the porosity, we decided to reduce the available area structuring the wafers before the anodic etching. The passage of flat substrates to micro-channels wafers requires the readjustment of some etching parameters due to the modification of electrical field distribution by the threedimensional shape structures in the wafer. As a result, macroporous silicon micro-channels have been realized on $5 \Omega \cdot \mathrm{cm}$, n-type, $(10$ o)-oriented and $525 \mu \mathrm{m}$-thick silicon wafers. The etching time was $45 \mathrm{~min}$ at current densities between 60 and $70 \mathrm{~mA} / \mathrm{cm}^{2}$. The diameters of the pores obtained were between about $900 \mathrm{~nm}$ and $1.2 \mu \mathrm{m}$ with a penetration in the silicon between 100 and $120 \mu \mathrm{m}$ (Figure 6). For microporous silicon micro-channels (pore diameter between 10 and $200 \mathrm{~nm}$ ) they were developed on $5 \Omega \mathrm{cm}$, (1 o o)-oriented, $525 \mu \mathrm{m}$-thick, ptype silicon wafers with current densities between 50 and $70 \mathrm{~mA} / \mathrm{cm}^{2}$ and an etching time of about $60 \mathrm{~min}$. As previously noted, a fallback of 50 and $5 \mu \mathrm{m}$ on $\mathrm{Si}_{3} \mathrm{~N}_{4}$ layer was observed around the preconcentration chamber and at the inlet and outlet of the channels, respectively, in order to obtain a significant porosity of the silicon side walls, as shown in Figure 7 . The porous structures involved in the different designs of micro-devices are mechanically stable under pressure and even during the adsorbent filling. 

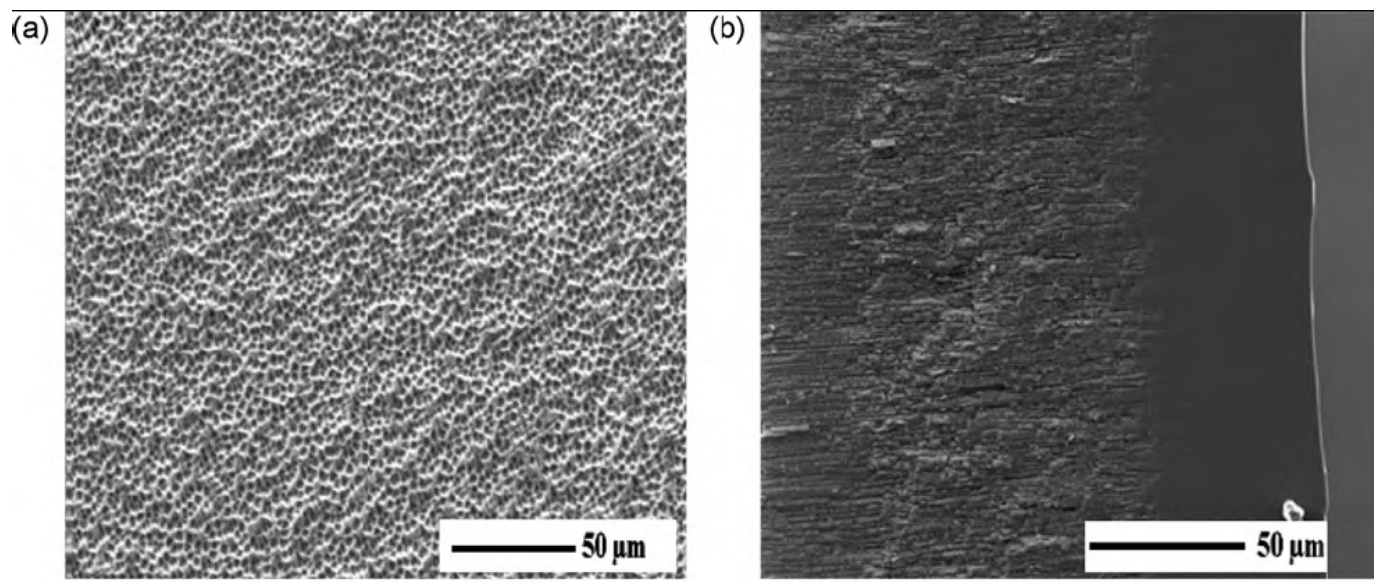

(c)

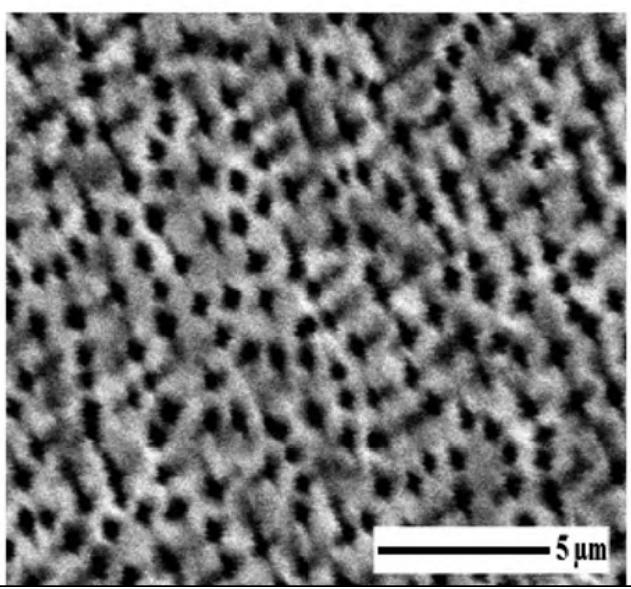

(d)

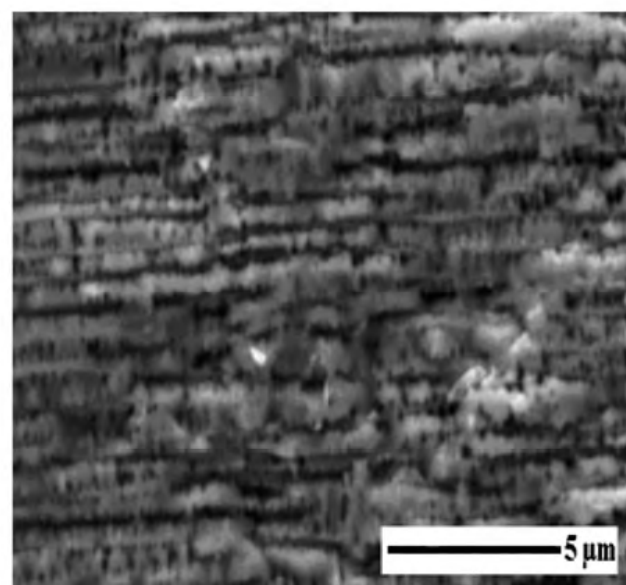

Figure 6: SEM images of micro-channels in porous silicon: (a) surface image of the micro-channel, (b) view of the cross section after cleavage of the device, (c) magnification of the surface image and (d) magnification of the cross section image.

Table 2 summarizes the effect of the various process parameters investigated on the nature, depth and specific surface of the pores formed in silicon. This table shows that for the p-type micro-channels, there was a significant reduction of the applied current density and a longer etching time compared with p-type flat substrates. However, for the n-type micro-channels, it was noticed an increase in both the etching time and the current density.

These macroporous silicon micro-channels with pores diameter between 0.9 and $1.2 \mu \mathrm{m}$ have been used for the carbon insertion described in Section III.2, while the microporous silicon micro-channels with pores diameter between about 0.05 and $0.25 \mu \mathrm{m}$ were especially dedicated to the preconcentration tests without adsorbent.

\section{III.2. Carbon insertion}

As mentioned before, the test on the carbon deposition consisted of two sets of experiments, the first of which was devoted to the deposition on silicon flat substrates by the wetting method and the second part dedicated to the filling in micro-channels from a fluidic solution. The first experiments have shown that for the same carbon solution and an identical wetting time, a thicker and more homogeneous layer of carbon is obtained on n-type macroporous silicon compared to non-porous silicon, as presented in Figure 8. This result reflects the fact that carbon particles fit into the silicon macropores forming a second binding surface for new particles and thus increasing the deposited quantity. 


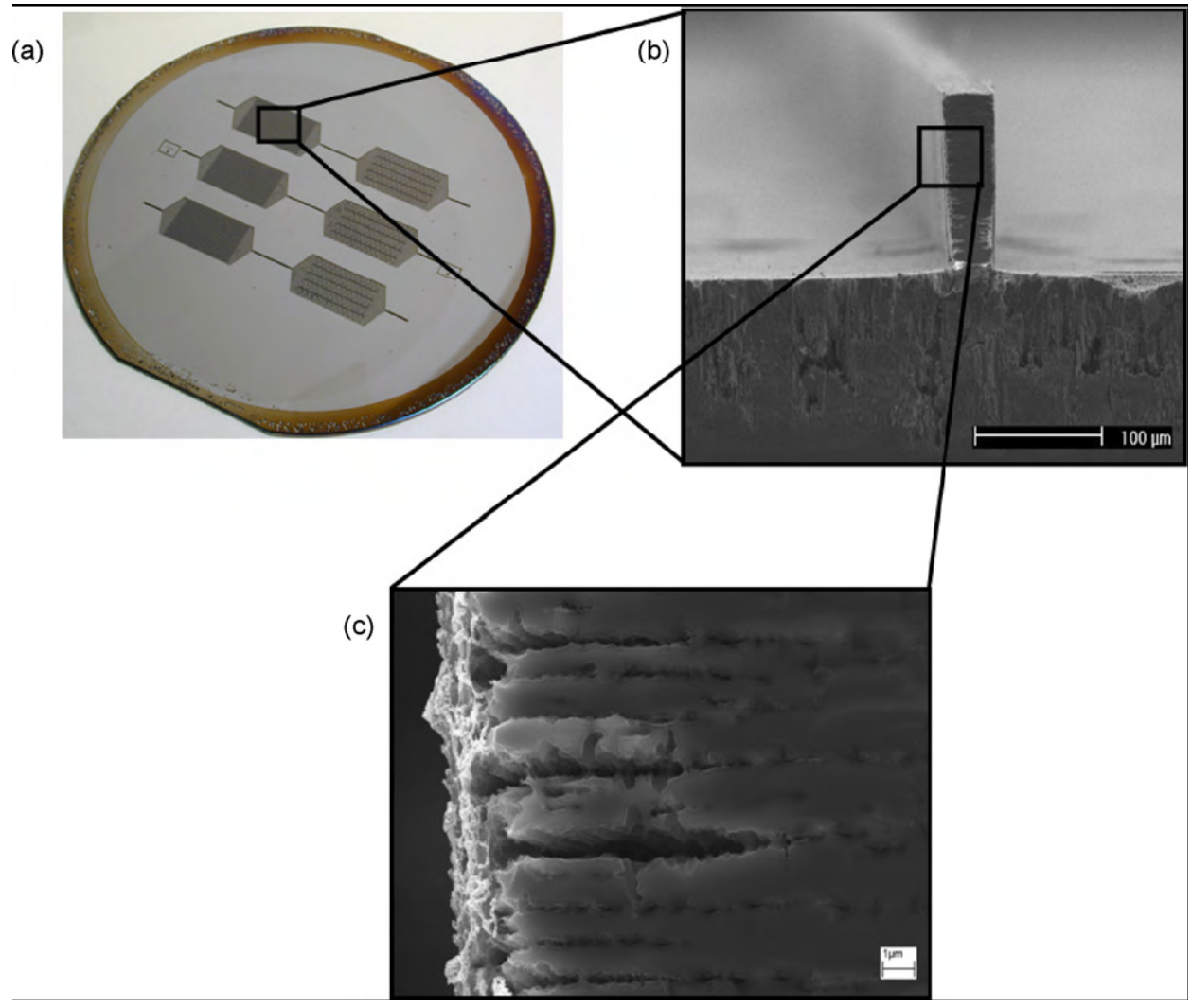

Figure 7: (a) Optical image of a silicon wafer including porous micro-channels, (b) SEM image of the cross section of a wall in "straight" design micro-channel and (c) magnification of the last wall image.

(a)

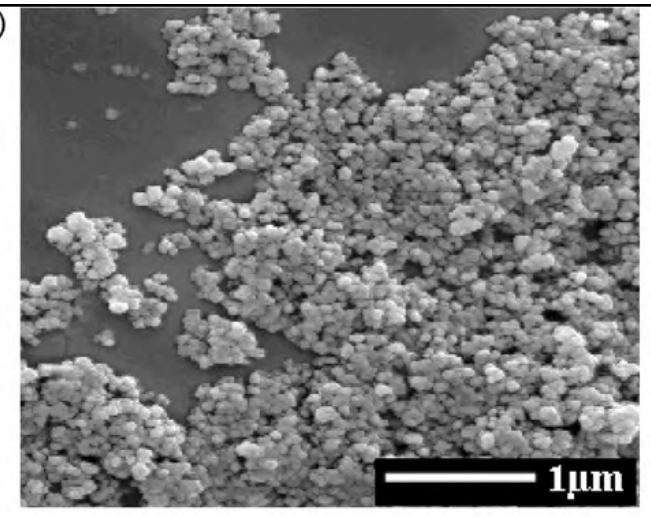

(c)

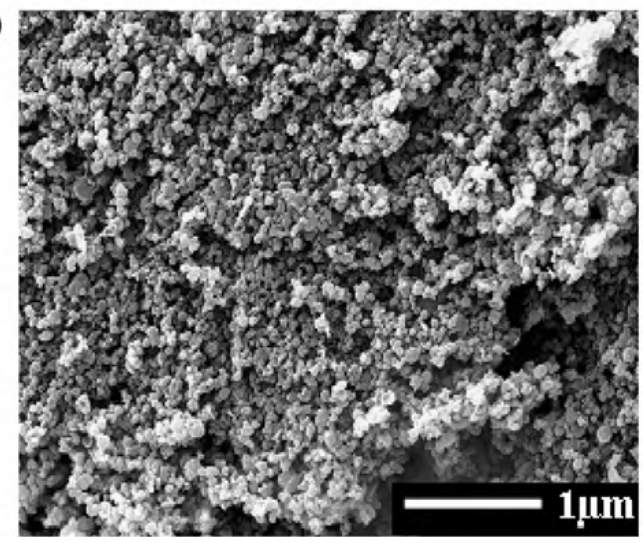

(b)

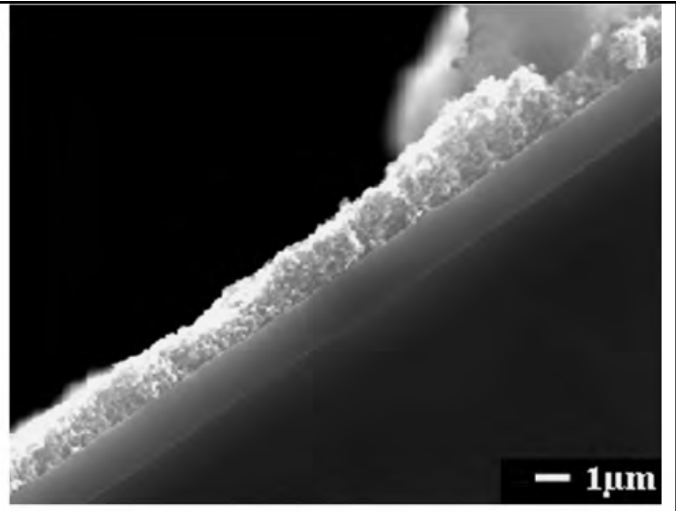

(d)

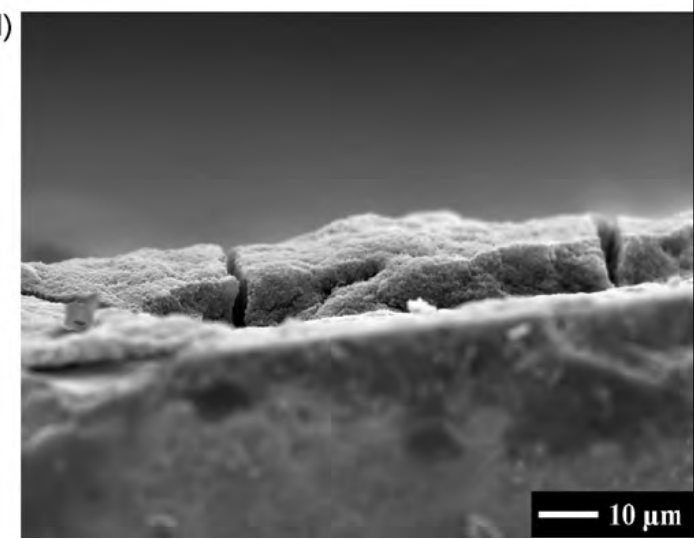

Figure 8: Top view and cross section SEM images of the carbon deposition on non-porous silicon $(a$ and $b)$ and porous silicon ( $c$ and $d$ ). 
The second part of experiments have shown that the quantity of carbon deposited in the silicon micro-channels is increased with the presence of structures with an efficiency that seems more important with the "zigzag" design and on porous silicon (Table 3). It was also observed that there is a significant overpressure from 3 to 4 bars in the micro-channels "straight" design after some carbon depositions unlike other designs which the loss charge is less than 1 bar. This overpressure can be caused by the higher surface covered in the preconcentration chamber by the structures in the straight design compared to other designs. In short, the overpressure leads to slowdown the progression of particles and to decrease the quantity of deposited carbon.

Table 3: Quantity of carbon filled in silicon micro-channels with three designs.

\begin{tabular}{|l|l|l|l|}
\hline \multicolumn{1}{|c|}{ Silicon micro-channels } & Straight & \multicolumn{1}{|c|}{ Zigzag } & Neutral \\
\hline Number of deposition & 3 & 3 & 3 \\
\hline Weight of deposited carbon $(\mathrm{mg})$ & $0.69 \pm 0.1$ & $3.67 \pm 0.1$ & $1.85 \pm 0.1$ \\
\hline
\end{tabular}

Regarding the distribution of the carbon solution in the micro-channels, the presence of structures in the preconcentration chamber is a key factor to homogenize the distribution of flows through the entire device. This was confirmed by the observation of a uniform deposition of carbon in the case of the designs with structures in opposition to the one without. Following these results, better homogeneity of the carbon deposited in the channels with structures, but appearance of an overpressure with the straight structures, we can conclude that the zigzag design is more adapted to the realization of micro-preconcentrators filled with a carbon powder from a fluidic solution.

It should be noted that the porous silicon aspect is an important factor for depositing carbon in large quantities in micro-channels. Indeed, we have made several experiments of carbon deposition on micro-channels which are summarised in Figure 9. It indicates that the contribution of porous silicon is estimated to increase the quantity of carbon deposited by about a factor 2 compared to non-porous silicon and that for whatever the design of the micro-channel is.

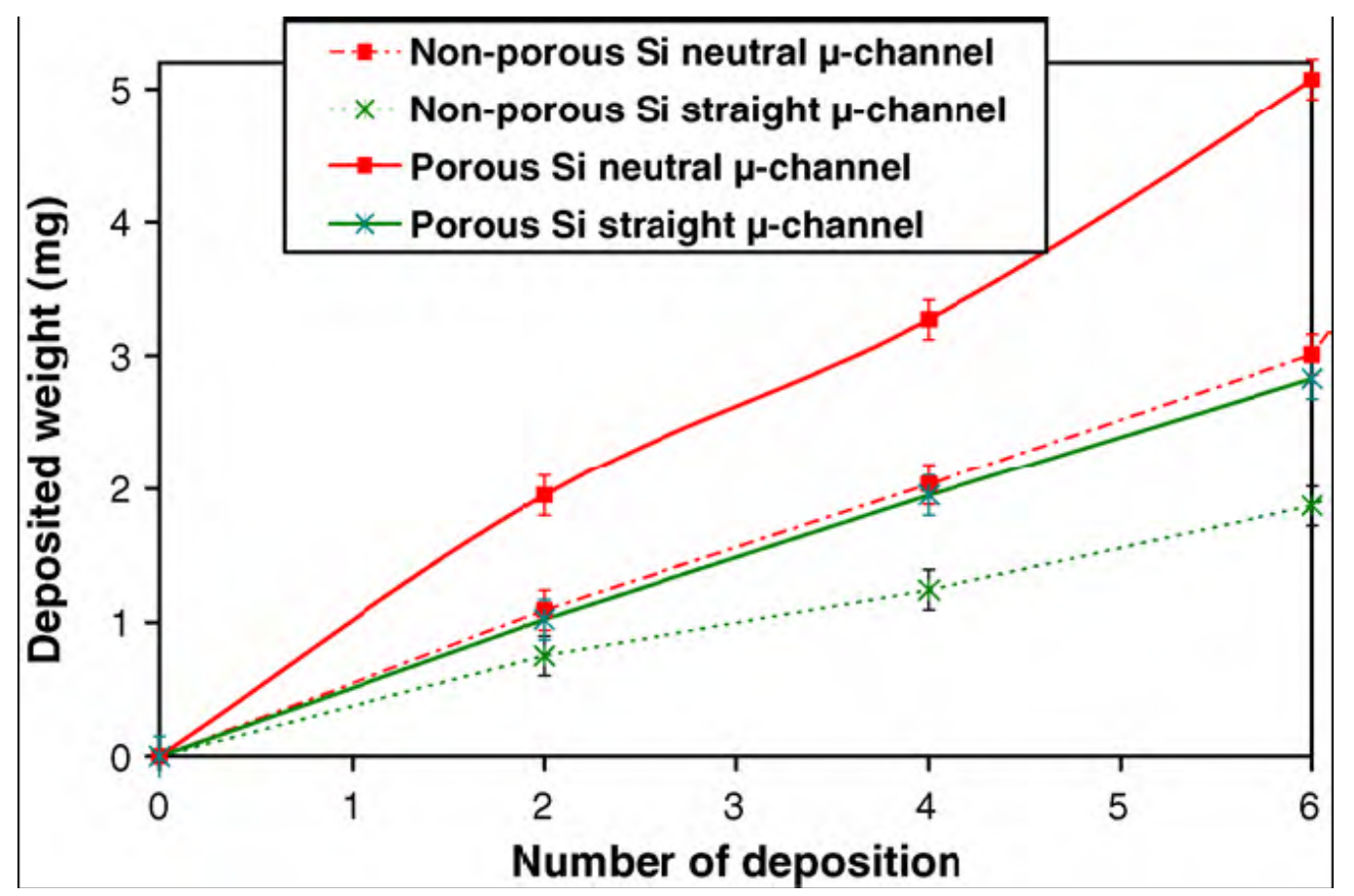

Figure 9: Quantity of carbon filled in porous and non-porous silicon micro-channels by fluidic solution depending on the design. 


\section{III.3. Preconcentration}

Following the conclusions drawn from the previous experiments presented in the earlier sections, the preconcentration tests have been performed on silicon and porous silicon microchannels with a "zigzag" design both without and with carbon. As previously reported only macroporous silicon was used for filling adsorbent while microporous silicon was dedicated solely to the preconcentration test without adsorbent. In order to study in similar conditions the contribution of porous silicon on the preconcentration, the quantity of deposited carbon on micro-channels with and without porous silicon will be sensibly equal to about $1 \mathrm{mg}$. To this effect, the number of deposits required will be reduced considerably and it is set at one for porous silicon micro-channels and two for those non-porous silicon microsytems (see Figure 9), simplifying the overall filling procedure, which is not negligible if we consider the manufacturing issue.

The first experiments consisted in determining the breakthrough time with silicon microchannels filled with the carbon powder. With $250 \mathrm{ppb}$ of benzene and a flow of $167 \mathrm{~mL} / \mathrm{min}$, we obtained at $25^{\circ} \mathrm{C}$ a breakthrough time of $28.6 \mathrm{~min}$ with a micro-channel filled with $0.90 \mathrm{mg}$ of carbon (Figure 10). This breakthrough time depends on the concentration and flow of gas for a given adsorbent mass. The dependence between the breakthrough time and the concentration of benzene is not linear since for our operating conditions, the breakthrough time is quite inversely proportional to the concentration of the pollutant gas and that whatever the mass of the adsorbent material as shown in Figure 11 obtained with a micro-channel filled with $10.2 \mathrm{mg}$ of carbon and tested in the same experimental conditions than the previous one. This result shows that for the detection of very low concentration as in the case of $250 \mathrm{ppb}$ of benzene, a large quantity of carbon is not necessary since, firstly, the breakthrough time is an increasing function of the deposited carbon mass and secondly, the breakthrough time obtained with $0.90 \mathrm{mg}$ of carbon deposition is long enough to cover the adsorption phase, with a duration fixed at $5 \mathrm{~min}$, of the preconcentration cycle.

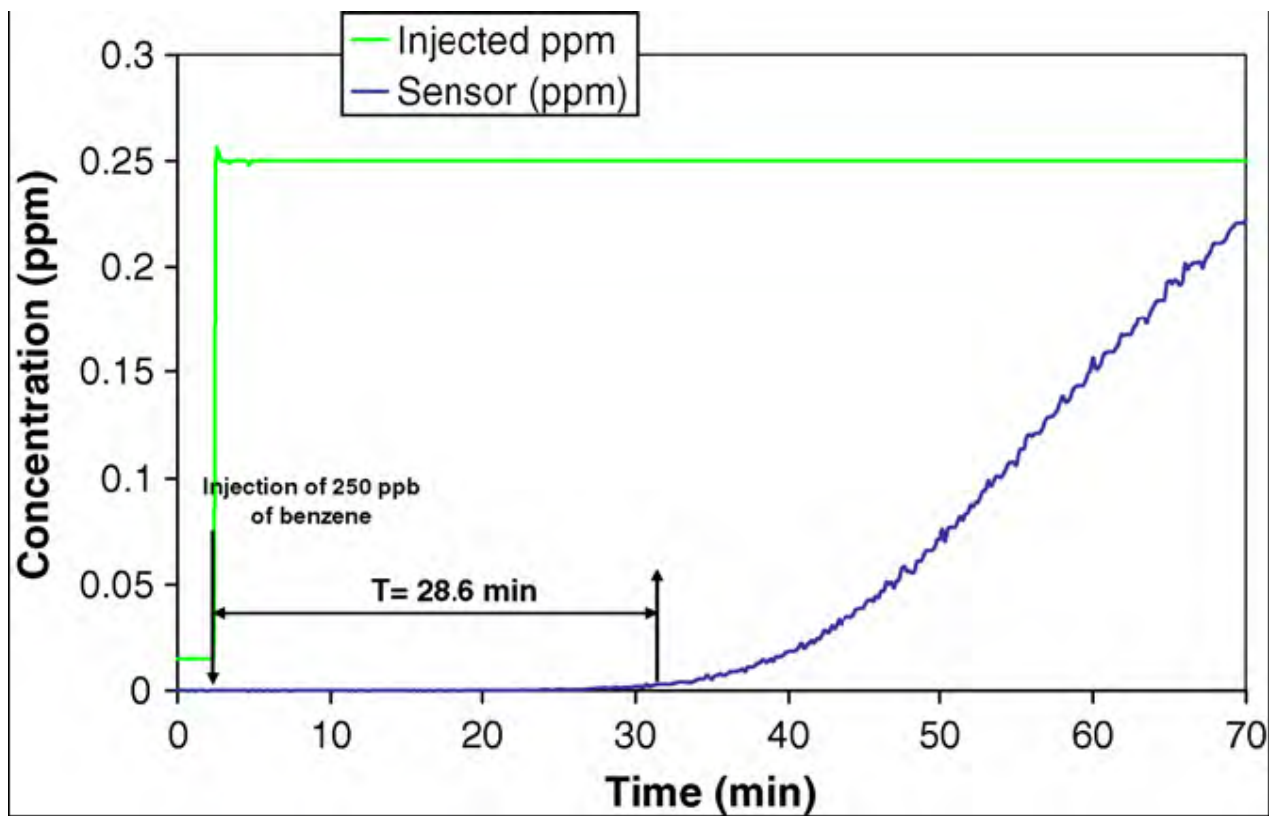

Figure 10: Breakthrough time determined with the response to benzene of the gas sensor placed after a microchannel filled with $0.90 \mathrm{mg}$ of carbon.

On the one hand, the non-porous silicon micro-channels filled with the carbon powder have been tested under benzene. The demonstration of the preconcentration with a non-porous silicon micro-channel containing $0.90 \mathrm{mg}$ of carbon nanopowder was realized at very low concentrations under $250 \mathrm{ppb}$ of benzene. During the adsorption phase of benzene no breakthrough was observed proving that all the injected quantity of pollutant was absorbed by the micro-preconcentrator. Then, in the desorption phase, during which the micro-channel 
was heated up to $200{ }^{\circ} \mathrm{C}$ with a heating rate of $160{ }^{\circ} \mathrm{C} / \mathrm{min}$, the maximum of concentration obtained at $196{ }^{\circ} \mathrm{C}$ is about $10 \mathrm{ppm}$ corresponding to a "practical" factor of preconcentration (as defined above) of about 40 (Figure 12).

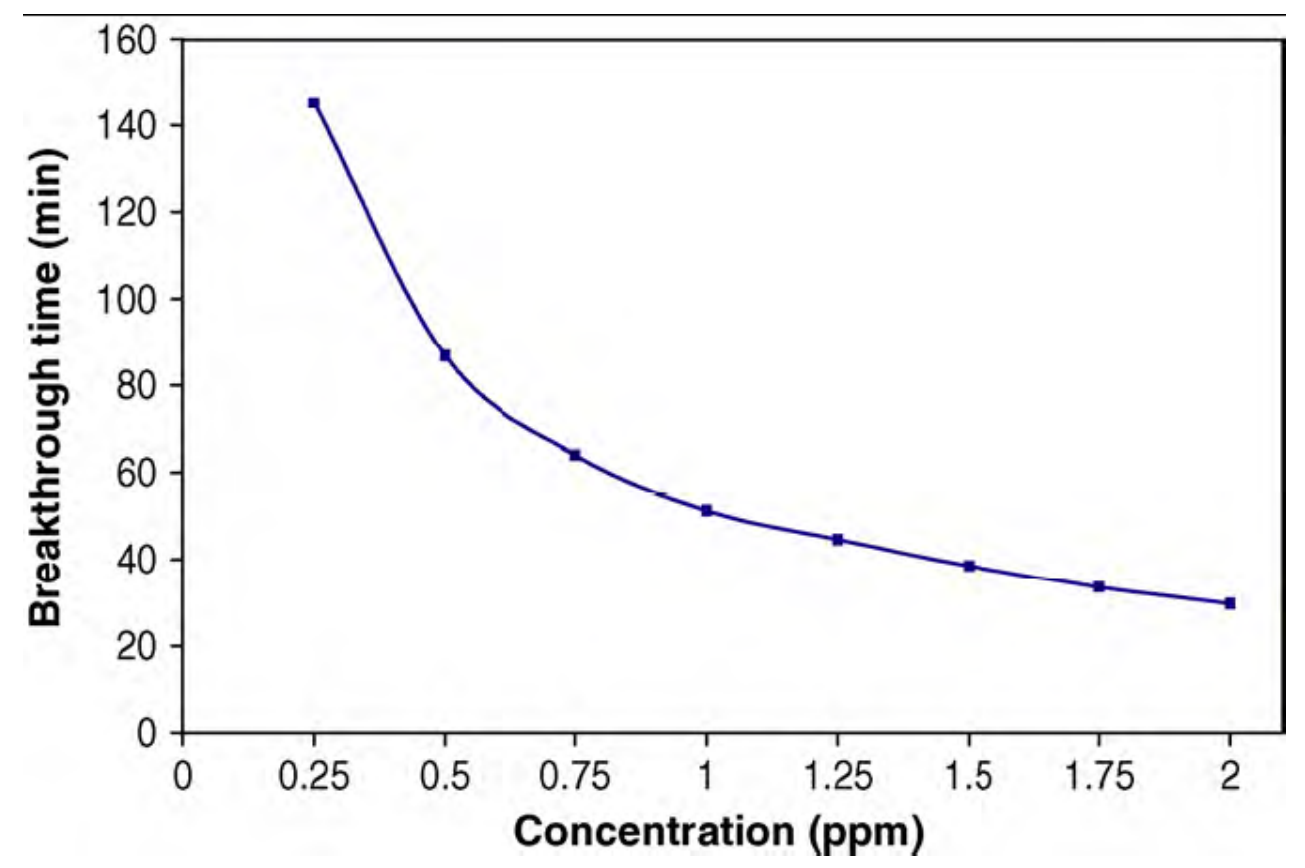

Figure 11: Breakthrough time as a function of the concentration of benzene for a micro-channel filled with $10.2 \mathrm{mg}$ of carbon.

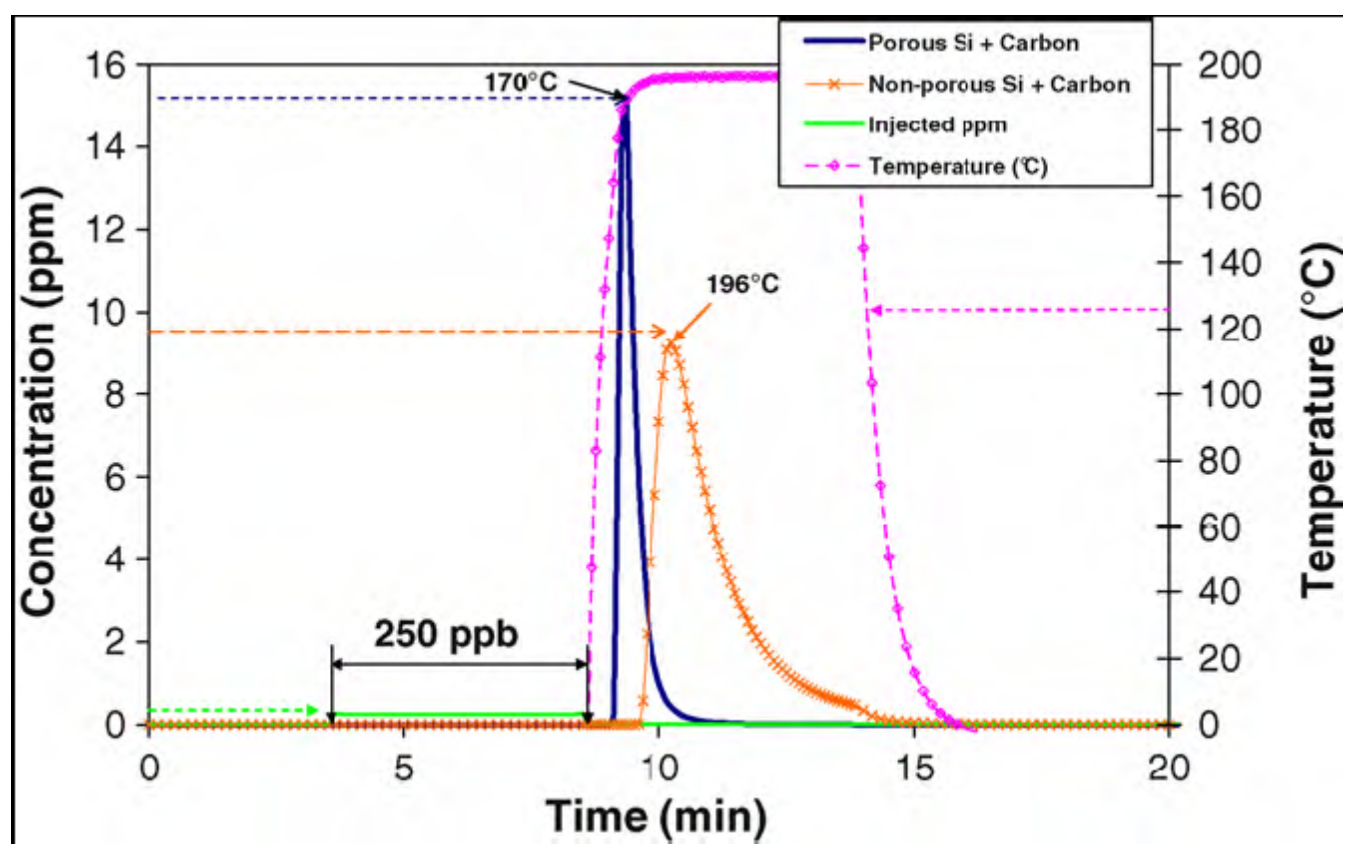

Figure 12: Comparison of gas sensor response between a porous silicon micro-channel filled with o.83 $\mathrm{mg}$ carbon and a non-porous silicon micro-channel filled with $0.90 \mathrm{mg}$ carbon after an adsorption step of $250 \mathrm{ppb}$ and desorption step at $200{ }^{\circ} \mathrm{C}$ with a heating rate of $160{ }^{\circ} \mathrm{C} / \mathrm{min}$.

On the other hand, we tested a microporous silicon micro-preconcentrator. First, this device without carbon was tested in order to validate our set-up. Interestingly, a low and incomplete adsorption was observed when benzene was injected in the micro-channels (1 ppm) and was confirmed during the desorption since a small desorption peak appeared at $80^{\circ} \mathrm{C}$ when the micro-channel was heated up to $200^{\circ} \mathrm{C}$. We believe that this low gas adsorption capacity of porous silicon in itself has some potential application in the field of preconcentration and 
deserves more consideration. It could be used directly as a gas adsorbent material. Following that, a macroporous silicon micro-preconcentrator containing $0.83 \mathrm{mg}$ was tested in similar conditions as those of non-porous silicon micro-preconcentrator. Indeed, such as in the case of non-porous silicon, no breakthrough is observed during the adsorption phase and when the micro-channel is heated up to $200{ }^{\circ} \mathrm{C}$ with a heating rate of $160{ }^{\circ} \mathrm{C} / \mathrm{min}$, (desorption phase), a desorption peak is obtained which the maximum reaches up to $16 \mathrm{ppm}$ at $17 \mathrm{O}^{\circ} \mathrm{C}$, corresponding to a "practical" factor of preconcentration of about 64 (Figure 12).

Unlike the preconcentrator made of non-porous silicon, the desorption of porous silicon preconcentrator was almost complete before the end of the heating cycle since the gas sensor reaches its normal baseline during this desorption phase. Thus, this result was confirmed when the heating rate applied was $5{ }^{\circ} \mathrm{C} / \mathrm{min}$ (Figure 13). From a calculation of activation energies of desorption from the different heating rates, the slow desorption of the pair nonporous silicon-carbon seems to be due to its activation energy of desorption bigger than the pair porous silicon-carbon one (6o versus $55 \mathrm{~kJ}$ ).

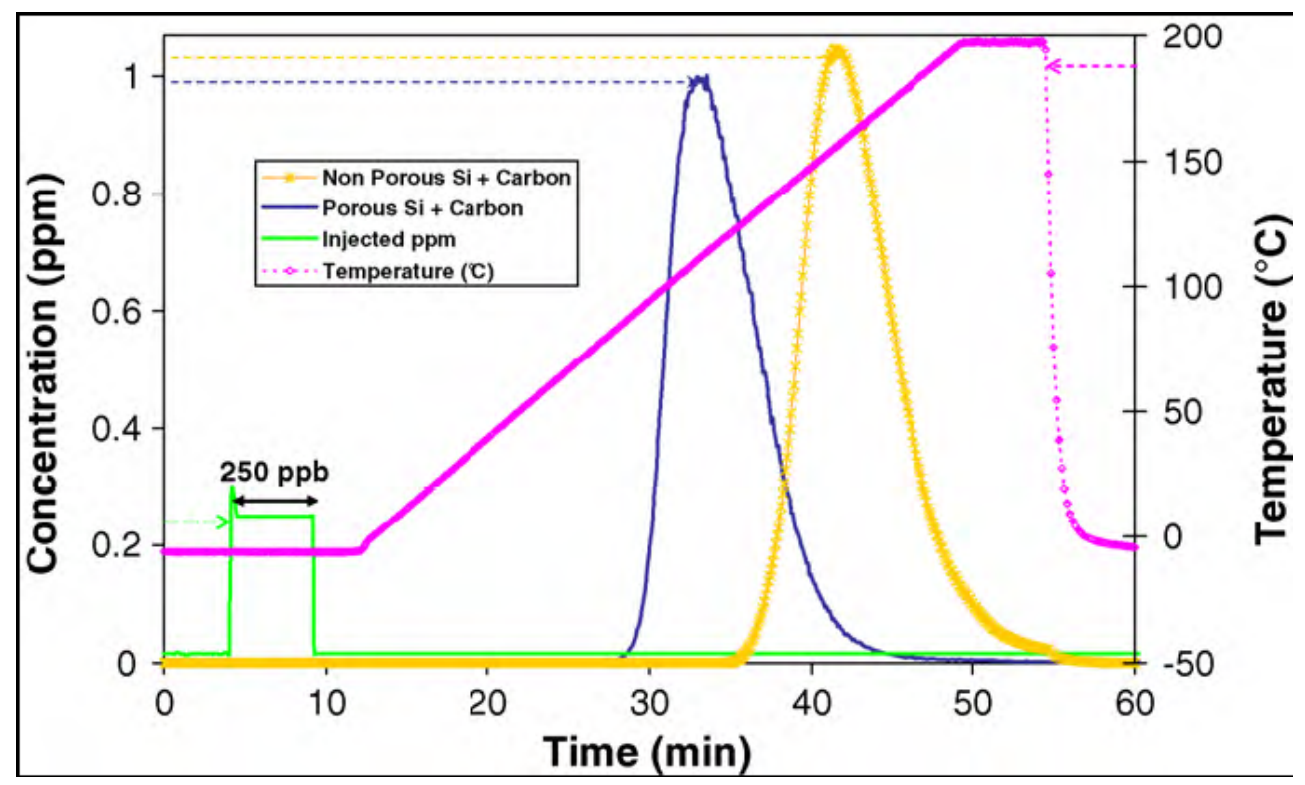

Figure 13: Comparison of gas sensor response between a porous silicon micro-channel filled with $0.83 \mathrm{mg}$ carbon and a non-porous silicon micro-channel filled with $0.90 \mathrm{mg}$ carbon after an adsorption step of $250 \mathrm{pb}$ and desorption step at $200{ }^{\circ} \mathrm{C}$ with a heating rate of $5{ }^{\circ} \mathrm{C} / \mathrm{min}$.

\section{Conclusions}

The effect of gas preconcentration with silicon micro-channels filled with carbon nanopowders was demonstrated. At the moment, with our experimental conditions and detection system, an adsorption time of 5 min provides a "practical" preconcentration factor of 55. This factor is largely dependent on the preconcentrator external parameters such as the detection system which we did not try to optimize in this paper.

One easy way to improve this result would be to remove the limitation linked to the flow rate. The device can withstand under high flow rate by increasing the diameter of the fluidic connectors at the inlet and outlet of the preconcentrator. The analytical calculations on the pressure drop levels show that a slight increase of this internal diameter to $385 \mu \mathrm{m}$ would lead to a decrease of the pressure drop below 200 mbar and allowed a significant increase of the flow rate and improved preconcentration factor.

The use of porous silicon has increased the quantity of deposited carbon in the microchannels because of the presence of pores on the surface of the preconcentration chamber constitutes an important asset to get a good binding layer and thus to increase the quantity of adsorbent filled in the micro-channel compared to non-porous silicon. The tests of these porous silicon micro-channels with carbon deposition have shown that the porous aspect of the micro-channels constitutes an important contribution to the performances of the 
preconcentrator. In fact, we have observed a total desorption of the pollutant in the case of the porous silicon preconcentrator filled with carbon in opposition to the non-porous silicon preconcentrator filled also with carbon. This result shows that the porous silicon, besides increasing the quantity of deposited carbon, contributes to the effectiveness of the gas preconcentration by making the desorption easier and thereby reducing the desorption temperature and at last the duration of the preconcentration cycle. This complete desorption of the pair porous silicon-carbon/benzene is, may be, due to its activation energy of desorption lower than the pair non-porous silicon-carbon/benzene one. In addition, the low gas adsorption capacity of porous silicon micro-channels without adsorbent is no less important. But the use of porous silicon itself as adsorbent material requires specific experimental conditions because its lower temperature of desorption reflects a fragile thermodynamic equilibrium with benzene molecules at room temperature $\left(25^{\circ} \mathrm{C}\right)$.

Currently we are evaluating the influence of water vapor on the preconcentration cycle, which we believe is an essential element insofar as this type of detector is intended for ambient air analysis which contains a relatively high humidity. In this type of application, carbon nanotubes and polymers appear to be promising materials in such environmental conditions. The interest of carbon nanotubes is related not only to their high specific area close to $1300 \mathrm{~m}^{2} / \mathrm{g}$ but also to the possibility to be functionalized by thermal or chemical treatment according to the compound to detect and to reduce their affinity to water.

\section{Acknowledgement}

Part of this work has been financially supported by the Rhône-Alpes region through Cluster «chimie».

\section{References}

[1] Th. Becker, St. Mühlberger, Chr. Bosch, V. Braunmühl, G. Müller, Th. Ziemann and K.V. Hechtenberg, Air pollution monitoring using tin-oxide-based microreactor systems, Sensors and Actuators B 69 (2000), pp. 108-119.

[2] B. Alfeeli and M. Agah, Selective preconcentration by temperature manipulation of cascaded micro-preconcentrators, Transducers 2009 Conference Denver, CO, USA, June (2009), pp. 1662-1665.

[3] S.M. Cho, Y. Jun Kim, G.S. Heo and S.-M. Shin, Two step preconcentration for analysis of exhaled gas of human breath with electronic nose, Sensors and Actuators B 117 (2006), pp. 50-57.

[4] W.A. Groves, E.T. Zellers and G.C. Frye, Analyzing organic vapors in exhaled breath using a surface acoustic wave sensor array with preconcentration: selection and characterization of preconcentrator adsorbent, Analytica Chimica Acta 371 (1998), pp. 131-143..

[5] F. Bender, N. Barié, G. Romoudis, A. Voigt and M. Rapp, Development of a preconcentration unit for a SAW sensor micro array and its use for indoor air quality monitoring, Sensors and Actuators B 93 (2003), pp. 135-141.

[6] W.A. Groves, E.T. Zellers and G.C. Frye, Analyzing organic vapors in exhaled breath using a surface acoustic wave sensor array with preconcentration: Selection and characterization of preconcentrator adsorbent, Analytica Chimica Acta 371 (1998), pp. 131-143.

[7] G. Serrano, H. Chang and E.T. Zellers, A micro gas chromatograph for high-speed determinations of explosive vapors, Transducers 2009 Conference Denver, CO, USA, June (2009), pp. 1654-1657.

[8] M. Martin, M. Crain, K. Walsh, R.E. McGill, E. Houser, J. Stepnowski, S. Stepnowski, H.-D. Wu and S. Ross, Microfabricaded vapor preconcentrator for portable ion mobility spectroscopy, Sensors and Actuators B 126 (2007), pp. 447-454.

[9] K. Persaud and G.H. Dodd, Analysis of discrimination mechanisms in the mammalian olfactory system using a model nose, Nature 299 (1982), pp. 352-355. 
[10] K. Song and S.-K. Lee, Development of a compact sample pré-concentration system for the detection of trace amount of volatile organic compounds (VOCs), Sensors and Actuators B 125 (2007), pp. 173-179.

[11] Edward T. Zellers, K.D. Wise, K. Najafi, R.B. Brown, Q.J. Cai and J. Driscoll, Determination of complex vapor mixtures in ambient air with a wireless microanalytical system: vision, progress, and homeland security applications, Technical Digest of the IEEE Conference on Technologies for Homeland Security Waltham MA, IEEE, Boston, November 13-14 (2002), pp. 92-95.

[12] C. Pijolat, D. Briand, Micro-preconcentrator for trace level detection of gases, MST News No. 4/07, 2007, pp 15-17.

[13] J.W. Gardner and P.N. Bartlett, Electronic noses: principles and applications, Measurement Science \& Technology 11 (2000), pp. 1087-11087.

[14] I. Gràcia, P. Ivanov, F. Blanco, N. Sabaté, X. Vilanova, X. Correig, L. Fonseca, E. Figueras, J. Santander and C. Cané, Sub-ppm gas sensor detection via spiral $\mu-$ preconcentrator, Sensors and Actuators B 132 (2008), pp. 149-154.

[15] P.R. Lewis, R.P. Manginell, D.R. Adkins, R.J. Kottenstette and D.R. Wheeler, Recent advancements in the gas-phase MicroChemLab, IEEE Sensors Journal 6 (3) (2006), pp. 784-795.

[16] C. Lu, W.H. Steinecker, W.-C. Tian, M.C. Oborny, J.M. Nichols, M. Agah, J.A. Potkay, H.K.L. Chan, J. Driscoll, R.D. Sacks, K.D. Wise, S.W. Pang and E.T. Zellers, Firstgeneration hybrid MEMS gas chromatograph, The Royal Society of Chemistry, Lab Chip 5 (2005), pp. 1123-1131.

[17] C. Roumanie, V. Pijolat, C. Meille, P. Bellefon, C. Pouteau and Delattre, Deposition of Pt-catalyst in a micro-channel of a silicon reactor: application to gas micro-TAS working at high temperature, Sensors and Actuators B 118 (2006), pp. 297-304.

[18] W.-C. Tian, H.K.L. Chan, C.-J. Lu, S.W. Pang and E.T. Zellers, Multiple-stage microfabricated preconcentrator-focuser for micro gas chromatography system, Journal of Micro-Electro-Mechanical Systems 14 (3) (2005), pp. 498-507.

[19] C. Pijolat, M. Camara, J. Courbat, J.-P. Viricelle, D. Briand and N.F. de Rooij, Application of carbon nanopowders for gas micro-preconcentrator, Sensors and Actuators B 127 (2007), pp. 179-185.

[20] H. Föll, M. Christophersen, J. Cartensen and G. Hasse, Formation and application of porous silicon, Materials Science and Engineering R39 (2002), pp. 93-141.

[21] J. Salonen, J. Tuura, M. Björkqvist and V.-P. Lehto, Sub-ppm trace moisture detection with a simple thermally carbonized porous silicon sensor, Sensor and Actuators B 114 (2006), pp. 423-426.

[22] P. Bettotti, L. Dal Negro, Z. Gaburro and L. Pavesi, P-type macroporous silicon for twodimensional photonic crystals, Journal of Applied Physics 92 (12) (2002), pp. 69666972. 